\title{
Assessoria às comunidades atingidas por projetos de mineração no entorno do Parque Estadual da Serra do Brigadeiro - MG
}

\author{
Assistance for people impacted by mining activity at Serra do Brigadeiro, in the State of Minas \\ Gerais, Brazil \\ Asesoría a las comunidades atingidas por proyectos de minería en el entorno del Parque Estadual \\ da Serra do Brigadeiro (Minas Gerais)
}

\begin{abstract}
Resumo
O presente artigo apresenta a experiência, bem como, alguns efeitos da atuação do Projeto de Assessoria às Comunidades Atingidas por Barragens e Mineração (PACAB), junto ao coletivo de atingidos por projetos minerários situados no entorno do Parque Estadual da Serra do Brigadeiro (PESB), Zona da Mata Mineira. A equipe deste Projeto, em decorrência de sua atuação, tem percebido uma persistência de violações no âmbito do direito à informação, do direito à participação, desprezo às identidades culturais, além de ameaças materiais e imateriais. Imbuído neste contexto, a organização coletiva dos atores sociais das comunidades assessoradas traz a pauta dos impactos da mineração nesse território.
\end{abstract}

Palavras-chave: Mineração; Assessoria; Zona da mata.

\begin{abstract}
This paper regards the actions of social projects dedicated to helping people who were impacted by dam failures and mining disasters at Serra do Brigadeiro, in the State of Minas Gerais, Brazil. The team that coordinates one of these projects has reported persistent civil rights violations along with direct and veiled threats. Under those circumstances, these collectives highlight the struggles of the locals who coexist with the effects of aggressive mining activity.

Keywords: Mining; Assistance; Minas Gerais.

\section{Resumen}

El presente artículo presenta la experiencia, bien como algunos efectos de la actuacion del "Projeto de Assessoria às Comunidades Atingidas por Barragens e Mineração" (PACAB), junto al colectivo de atingidos por proyectos minería situados en el entorno del Parque Estadual da Serra do Brigadeiro (PESB), Zona da Mata del estado de Minas Gerais. El equipo de este proyecto, en consecuencia de tu actuación, ha percibido una persistencia de violaciones en el ámbito del derecho a la información, del derecho a la participación, desprecio a las identidades culturales, además de amenazas materiales y no materiales. Imbuido en este contexto, la organización colectiva de los actores sociales de las comunidades asesoradas trae la pauta de los impactos de la minería en ese territorio.
\end{abstract}

Palabras clave: Minería; Asesoría; Zona da Mata.

\section{Introdução}

A Zona da Mata Mineira, no contexto do período Colonial, foi considerada um território estratégico para os intentos da coroa portuguesa, não somente por deter vastas jazidas de recursos naturais, mas, sobretudo, por ter desempenhado, durante várias décadas, uma barreira natural à evasão das riquezas minerais da região aurífera. Ainda que seu nome remeta à 
exuberante floresta natural, uma das características atuais de sua paisagem é, paradoxalmente, a ausência de matas. A vegetação original foi substituída, por cafezais e, em seguida, por diversas pastagens; atualmente, apenas os topos de algumas elevações possuem sinais de florestas residuais. Do século XVIII até a década de 1930, várias famílias tradicionais da mineração migraram para a Zona da Mata no afã de expandir seus negócios, visto que naquela ocasião, o café havia impulsionado a economia, atraindo o desenvolvimento industrial, comercial e financeiro. Após 1930, com o declínio do primeiro ciclo cafeeiro e início da industrialização, essa região entra em decadência econômica e política em detrimento de outras regiões do Estado. Em 1970, projetos desenvolvimentistas são paralisados, a agropecuária é desenvolvida de forma tradicional, voltada ao mercado local e regional, com exceção da cafeicultura que conseguiu exportar seu produto, contudo sem promover o crescimento regional (Netto \& Diniz, 2006).

Já nas últimas décadas, Zhouri e Rothman, (2008), apontam que o aumento da demanda energética, contribuiu para que um conjunto de projetos hidroelétricos fossem construídos na Zona da Mata Mineira. Contudo, foram nos últimos anos, que a mineração ganhou destaque, principalmente no entorno do Parque Estadual da Serra do Brigadeiro (PESB), região detentora de uma das maiores reservas de bauxita do Brasil. Nesse sentido, segundo Iorio e Magno (2019, p. 35) a Companhia Brasileira de Alumínio (CBA) vem demonstrando interesse nas reservas de bauxita da Serra do Brigadeiro desde os idos de 1950.

A partir da instalação desses empreendimentos, uma gama de conflitos é desencadeada, provocando uma série de mobilizações entre os atingidos e militantes da causa ambiental, cujo fim é a manutenção de seus modos de vida, a soberania de seus territórios e a garantia de preservação dos recursos naturais. Esse contexto permitiu que fosse formada uma rede de resistência à esses empreendimentos minerários e hidroelétricos.

Assim, tais atores sociais, são percebidos enquanto defesa do lugar, da reafirmação identitária e da relação de pertencimento. A Zona da Mata Mineira, portanto, conta com a experiência de diversos coletivos de resistência à empreendimentos, cuja amplitude de danos é sobremodo devastadora. Essa realidade contribuiu para que diversos grupos na região, entre eles pesquisadores da Universidade Federal de Viçosa (UFV), criassem em 1996 o Projeto de Extensão Universitária direcionado a Assessoria às Comunidades Atingidas por Barragens ( PACAB $^{1}$ ), que, na última década (20102020), incluiu em seu escopo de trabalho, a palavra Mineração. O projeto surge então com objetivo de assessorar famílias atingidas por barragens hidroelétricas e mineração. Além disso, ao longo desses anos, o PACAB tem contribuído na organização de grupos como ONG's, agricultores familiares, e atingidos por empreendimentos minerários e hidroelétricos na região da Zona da Mata Mineira (Oliveira, 2015).

Desse modo, o objetivo do presente artigo é apresentar a experiência de Extensão Universitária junto às comunidades atingidas por mineração, na região do Parque Estadual da Serra do Brigadeiro, bem como trazer luz ao debate acerca dos impactos provocados pela mineração na região de atuação do referido projeto.

\section{Metodologia}

O presente artigo traduz-se na sistematização dos esforços convergidos e experiências adquiridas pelo Projeto de Extensão Universitária direcionado a Assessoria às Comunidades Atingidas por Barragens e Mineração (PACAB) junto às comunidades atingidas pela mineração na região do Parque Estadual da Serra do Brigadeiro. Nesse sentido, conforme prelecionam Pereira et al (2018, p.67), o "Método é o caminho para se realizar alguma coisa e quando se tem o caminho, torna-

\footnotetext{
${ }^{1}$ O PACAB é um projeto de extensão-pesquisa que atualmente (2021) é coordenado por um professor doutor do Departamento de Economia Rural da UFV com formação na área de Ciências Sociais, com ênfase em meio ambiente, impactos ambientais e comunidades rurais e tradicionais. Além disso, o projeto conta com a parceria de outros professores nas áreas de História, Direito, Ciências Sociais, Geografia e Dança, todos professores da UFV. No âmbito discente, o projeto tem envolvido alunos de graduação principalmente dos cursos de Ciências Biológicas, Ciências Sociais, Cooperativismo, Geografia e Direito, bem como alunos do curso de pós-graduação dos programas de Extensão Rural e Economia Doméstica.
} 
se mais fácil realizar viagens sabendo onde se está e aonde se quer chegar e como fazê-lo", desse modo o método empregado nesta pesquisa, seguiu pelo viés qualitativo; através do estudo de caso pois, esse instrumento permitiria conhecer com mais amplitude o como e o porquê de uma dada situação ou contexto, em que, se supõe ser única em muitos aspectos, procurando descobrir o que há nela de essencial e característico (Fonseca, 2002. p. 33).

Nessa conjuntura, o PACAB traz a experiência de trabalho junto às comunidades atingidas. Movimentos sociais, sindicatos e pesquisadores que atuam, sobretudo, nos municípios de Rosário da Limeira (MG) e Muriaé (MG), são bem-vindos e agregam nos âmbitos dos debates e discussões. O município de Muriaé (MG) faz parte do entorno do Parque Estadual da Serra do Brigadeiro (PESB), que é composto por oito municípios: Ervália (MG), Fervedouro (MG), Sericita (MG), Araponga (MG), Miradouro (MG), Pedra Bonita (MG), Muriaé (MG) e Divino (MG). Esse território possui uma área de 2.953 km² e uma estimativa para o ano de 2019 de aproximadamente 176 mil habitantes.

Segundo Fenelon (2018), em 2003, esses municípios, juntamente com o município de Rosário da Limeira (MG), vão compor o Território Rural da Serra do Brigadeiro passando, assim, a integrar ao Programa Nacional de Desenvolvimento Sustentável de Territórios Rurais (PRONAT), do extinto, Ministério do Desenvolvimento Agrário (MDA).

Cabe salientar que essa região representa um dos últimos fragmentos da Mata Atlântica com grande extensão de florestas contínuas do Estado de Minas Gerais. Inserido entre picos rochosos de um prolongamento das Serras da Mantiqueira e Caparaó, abriga tanto espécies endêmicas da Mata Atlântica quanto da própria Serra do Brigadeiro, além de ser refúgio de espécies em risco de extinção, como é o caso do muriqui Brachyteles hypoxanthus, maior primata das Américas. A vegetação do parque apresenta características ombrófilas, com ocorrência de campos de altitude junto às porções mais elevadas. As áreas de floresta são, sobretudo, secundárias, devido ao grande desmatamento ocorrido outrora. As florestas primárias ocupam apenas as áreas mais inacessíveis do Parque. Os solos da região, de modo geral, são pobres em nutrientes (distróficos) e com altos teores de alumínio podendo apresentar elevados teores de matéria orgânica (Benites, 1998).

Segundo Fenelon (2018), outra característica encontrada no entorno do Parque é a forte presença de agricultores familiares e de agricultores agroecológicos, que vivem apreensivos com a exploração de bauxita na região. Nesta área encontra-se uma das maiores reservas de bauxita do Brasil, matéria prima para o alumínio, explorada pela Companhia Brasileira de Alumínio (CBA), portanto, a mineração no entorno do PESB, por se tratar de uma atividade potencialmente causadora de impactos ambientais, representaria uma ameaça à UC. Na Figura 1, a seguir, é possível observar uma imagem da região, onde apresenta áreas de destaque de preservação ambiental e de potencial minerário. 
Figura 1. Imagem da Região do PESB contendo Unidades de Conservação e área de potencial exploração minerária.

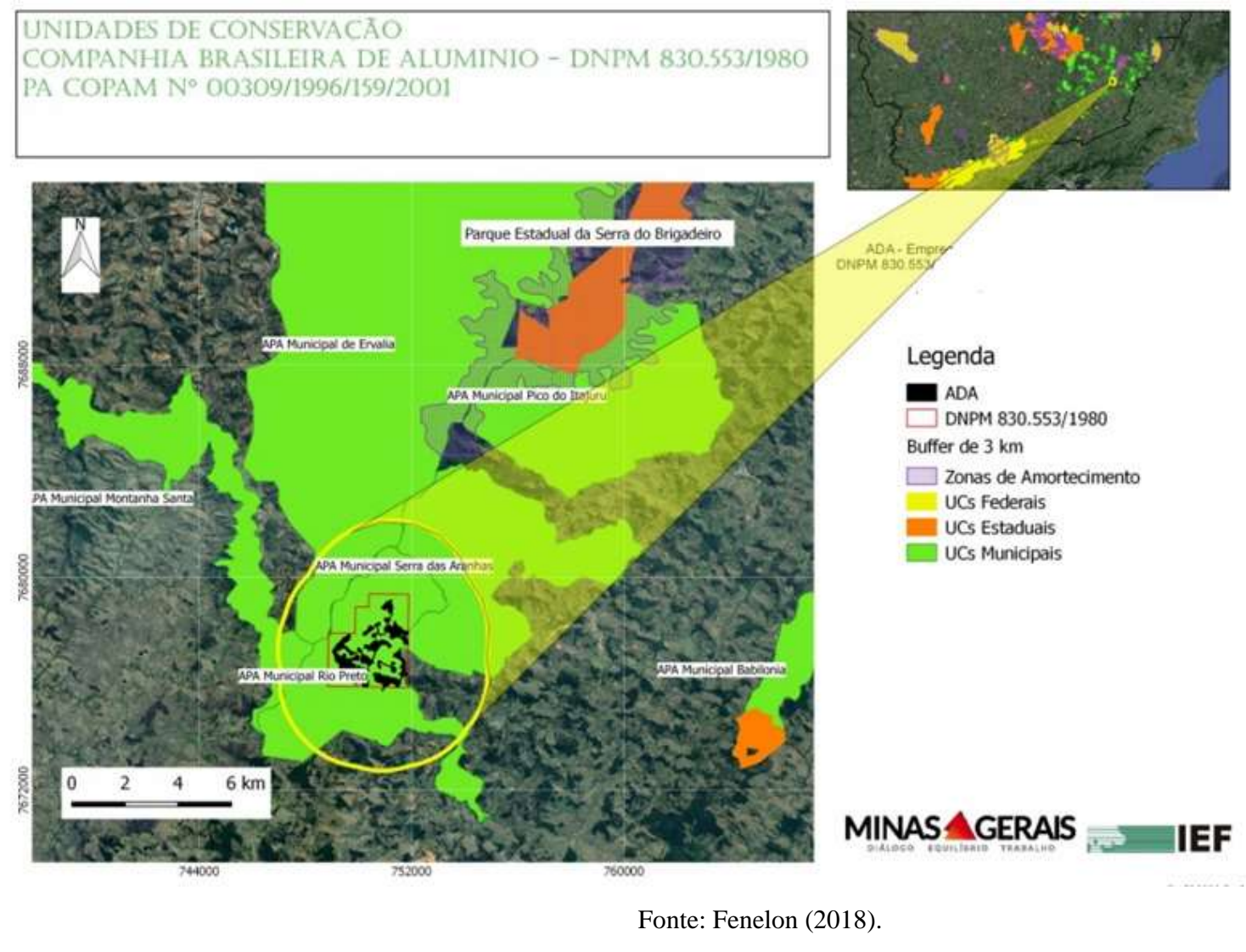

Portanto, os objetivos do Projeto têm sido na contribuição da organização das comunidades que poderão ser diretas e/ou indiretamente afetadas quanto aos planos de expansão dos projetos de mineração e seus impactos socioambientais na região do PESB. Desta forma, o PACAB, tem pautado através de uma relação dialógica entre os membros do Projeto e as comunidades, contribuindo na organização comunitária, acompanhamento nos processos de licenças ambientais, processo de negociação, participação em audiências públicas e assembleias populares, bem como na mobilização e divulgação dos possíveis impactos provocados pela mineração.

Os membros do Projeto entendem que a proposta metodológica deve ser compreendida como uma ação de mediação, troca de aprendizado entre os membros do Projeto e os atingidos, enfim, a valorização da participação conjunta. Desta forma, as ações realizadas pelos técnicos possibilitam e incentivam espaços propícios à realização de dinâmicas interativas e discursivas, permitindo a direção política do processo, ou seja, resultado de consensos construídos pelos próprios atores sociais envolvidos, tendo como referencial teórico os estudos realizados por Paulo Freire (Freire, 1988). Cabe ressaltar que esta metodologia se apresenta de forma flexível, respeitando o processo histórico, a realidade e o ritmo de aprendizagem das pessoas envolvidas.

No acompanhamento do Projeto, foram realizadas reuniões com a equipe a fim de discutirem dois objetivos: primeiro, as estratégias e contribuições da equipe junto aos parceiros e comunidade, e, segundo, por meio de estudos de textos relacionados à temática da mineração, dos conflitos ambientais e mobilizações sociais, possibilitando dessa forma, capacitar a equipe promovendo uma relação entre extensão e ensino.

Do ponto de vista acadêmico, o PACAB tem contribuído no mapeamento de conflitos ambientais na Zona da Mata Mineira, o que permite formar uma base de dados sobre a relação espacial de projetos de mineração, usinas e Pequenas Centrais Hidrelétricas $(\mathrm{PCH})$ neste território. Essa outra face do Projeto permite trazer elementos que ajudam a discutir com a 
comunidade universitária os impactos ambientais oriundos da construção e instalação de barragens e projetos minerários, bem como a partir das pesquisas desenvolvidas fornecer elementos de discussão técnica e teórica que possam subsidiar o apoio e assessoramento aos atingidos.

\section{Resultados e Discussão}

O significativo patrimônio mineral inerente ao Brasil o ascende à condição de um dos maiores produtores e exportadores de minerais do mundo (o minério de ferro lidera com $60 \%$ do valor total da produção mineral brasileira). Assim, mesmo que notórias as consequências desses empreendimentos, a indústria extrativista mineral tem sido impulsionada sobremaneira por meio de um elevado investimento: somente nos últimos 10 anos, o valor da produção cresceu $550 \%$. E os investimentos para o setor, entre 2012 e 2016, foram de US\$ 75 bilhões (Araujo, 2014. p. 01). Ou seja, de um lado a política governamental brasileira, incentiva, concede facilidades e fomenta tal exploração - de outro, subestima os danos ambientais em detrimento aos recursos financeiros.

Para Fenelon (2018), as formas como a exploração dos recursos minerais vêm sendo conduzidas no Brasil, milhares de toneladas de minério extraídas ao ano, desde sempre, tem sido especulada e realizada por meio de grandes empresas nacionais e, sobretudo pelas multinacionais. Ressalta-se que a indústria extrativista mineral se encontra no rol das atividades antrópicas que mais provocam impactos socioeconômicos e ambientais, modificando territórios e ameaçando uma série de alternativas de vida, de produção e de renda. Nesse enredo a presença de movimentos sociais contestadores ao modelo mineral vigente atuam no sentido de denunciar, enfrentar e buscar alternativas para as constantes ameaças desses empreendimentos aos territórios impactados. Essa teia vai favorecer com que ONGs, sindicatos, movimentos sociais, dentre outras organizações afins, se organizem ao passo em que afloram conflitos e embates no âmbito da implementação de empreendimentos mineradores.

Nessa trajetória, o aprendizado de mundo desses grupos é ampliado, novas formas de conceber e de compreender as mazelas do capital transparecem: a exploração, a fragmentação de comunidades, os impactos ambientais, a mensuração de danos (Guedes, 2015). No decorrer desse caminho, a compreensão de seus direitos e de lutar por eles vem sendo adquirida. Assim, Silva et al $(2018$, p.10) prelecionam que "[d]e um modo geral, os recursos minerais são importantes para o desenvolvimento econômico de uma sociedade, porém, ao serem extraídos desencadeiam uma série de impactos positivos e negativos que afetam diretamente a natureza e a qualidade de vida da população."

Neste contexto Magno (2017), destaca que no entorno do Parque Estadual da Serra do Brigadeiro (PESB), principalmente a partir do início deste século, a Companhia Brasileira de Alumínio (CBA), tinha enquanto objetivo, expandir suas unidades de extração de bauxita. Segundo este mesmo autor, a partir de 2004, um conjunto de organizações, a exemplo de Sindicato dos Trabalhadores Rurais, Comissão Pastoral da Terra (CPT), ambientalistas, dentre outros, constituíram "uma articulação discursiva contrária ao avanço da mineração no território do PESB denominada enquanto - Comissão Regional dos Atingidos pela Mineração de Bauxita (CRAM)” (Magno, 2017, p.219).

Instituída, tal comissão passa a articular juntamente com outros grupos da região, podendo-se citar a Campanha Pelas Águas $^{2}$, que surgiu em Viçosa (MG) com a missão de contrapor o projeto de implantação de um mineroduto na região; outrossim, com o Movimento Popular Pela Soberania Popular na Mineração (MAM) dentre outros, e assim, passa a consolidar a rede de resistência na região.

\footnotetext{
2 A Campanha Pelas Águas em Viçosa, foi um movimento organizado por diversos grupos e entidades, inclusive com a participação do PACAB, que trouxeram para a discussão os possíveis impactos que seriam provocados pela possibilidade de passagem na microrregião de Viçosa-MG de um mineroduto da Empresa Ferrous Resources do Brasil.
} 
Além disso, é importante destacar que, em novembro de 2015, ocorreu um dos maiores rompimentos de barragem de rejeitos de minério no Brasil ocorrido no município de Mariana (MG). Tal barragem pertencia às empresas Samarco/Vale e BHP Billiton Brasil Ltda. Foram mais de 50 milhões de metros cúbicos de resíduos minerais, percorrendo as águas do Rio Doce, contaminando todo o curso desse rio e entorno de suas margens. Aproximadamente 600 quilômetros entre o local do rompimento até sua foz junto ao litoral capixaba. Esse crime ambiental, situado e ocorrido a pouco mais de 200 quilômetros dos municípios do PESB, trouxe a motivação necessária para mobilização do coletivo e assim, o desencadeamento de diversos debates na região.

Nesse sentido, Magno et. al. (2017) apresentam um levantamento referente ao período compreendido entre os anos 2000 e 2011 dos principais acontecimentos atinentes aos intentos da mineração de bauxita, bem como mobilização de resistência à mineração nas proximidades do Parque Estadual da Serra do Brigadeiro. No quadro, a seguir, pode-se observar o levantamento realizado pelos autores retromencionados, com a atualização de importantes eventos ocorridos na região nos últimos 20 anos.

Quadro 1. Eventos de Resistência contra a mineração no entorno do Parque Estadual da Serra do Brigadeiro-MG.

\begin{tabular}{|c|c|}
\hline Ano & Síntese de Acontecimentos \\
\hline 2000-2004 & $\begin{array}{l}\text { A Companhia Brasileira de Alumínio CBA retoma as pesquisas na região do entorno do Parque estadual do } \\
\text { Brigadeiro. O que provoca mobilizações dos sindicatos dos trabalhadores rurais da região como o do município } \\
\text { de Miradouro, Rosário da Limeira, entre outros. Essa mobilização vai desemborcar em uma audiência pública } \\
\text { com a Superintendência do Meio Ambiente de Minas Gerais (SUPRAM - Regional Zona da Mata) no } \\
\text { município de Rosário da Limeira. E, posteriormente é criada uma Comissão uma Comissão de enfrentamento a } \\
\text { mineração na região, com representantes, de ONG’s, Sindicatos de Trabalhadores Rurais, Comissão Pastoral da } \\
\text { Terra (CPT), entre outros }\end{array}$ \\
\hline $2005 / 2008$ & $\begin{array}{l}\text { Nesse período ocorre na região rompimento de barragens de rejeitos de minérios, nos municípios de Miraí e } \\
\text { Muriaé causando diversos danos socioambientais. Esses rompimentos provocam novas mobilizações, } \\
\text { assembleias populares, Audiências Públicas, Romarias e outros atos. Agora contando com a participação do } \\
\text { Movimento dos Atingidos por Barragens (MAB-MG). }\end{array}$ \\
\hline $2009 / 2011$ & $\begin{array}{l}\text { Nesses anos são construídos encontros debatendo os impactos da mineração na Região, mobilização popular } \\
\text { contra a construção de nova barragem de rejeitos no entorno da Serra do Brigadeiro. Nesse período a CBA } \\
\text { realiza reuniões com as comunidades, Sindicatos de trabalhadores Rurais, contrata uma ONG para promoção de } \\
\text { educação ambiental. }\end{array}$ \\
\hline 2012-2016 & $\begin{array}{l}\text { Intensificação e fortalecimento da resistência, mobilizações nos municípios do entorno do PESB. Troca de } \\
\text { experiência com a mobilização ocorrida contra o mineroduto da Empresa Ferrous Resources na região de } \\
\text { Viçosa. Criação da Campanha "Mineração Aqui Não". Participação do MAM-MG na articulação e nos debates! }\end{array}$ \\
\hline 2017-2021 & $\begin{array}{l}\text { Frei Gilberto liderança em Belisário distrito de Muriaé é ameaçado de morte, o caso toma grandes proporções } \\
\text { sendo inclusive tendo o envolvimento da Comissão de Direitos Humanos da Assembleia Legislativa de Minas } \\
\text { Gerais, investigando o caso. Nestes anos a Comissão de enfrentamento criada, faz diversas reuniões nas } \\
\text { comunidades da região debatendo o problema dos impactos da mineração, a valorização da agricultura familiar } \\
\text { e agroecologia. A partir de } 2020 \text { com a pandemia de Covid-19 as mobilizações continuaram, através de } \\
\text { carreatas e passeatas respeitando as normas sanitárias. }\end{array}$ \\
\hline
\end{tabular}

Fonte: Magno et. al., (2017) e Pesquisa de campo dos autores entre 2016 a 2021.

A partir desse cenário, a equipe do $\mathrm{PACAB}$, subsidiada por experiências anteriores, passa a contribuir junto à organização de potenciais atingidos na região do PESB, principalmente àqueles que vivem nas comunidades de Belisário, distrito de Muriaé (MG), bem como assessorando a população das comunidades rurais do município de Rosário da Limeira (MG). Em meio a este processo de organização, o Projeto tem participado das mobilizações, assembleias populares, reuniões e audiências. A figura a seguir apresenta um cartaz que convoca a população para uma assembleia popular sobre o tema. Desta forma essas mobilizações têm trazido a luz ao debate acerca da mineração e seus impactos nesses territórios. 
Figura 2. Cartaz de mobilização para realização de reunião em Rosário da Limeira

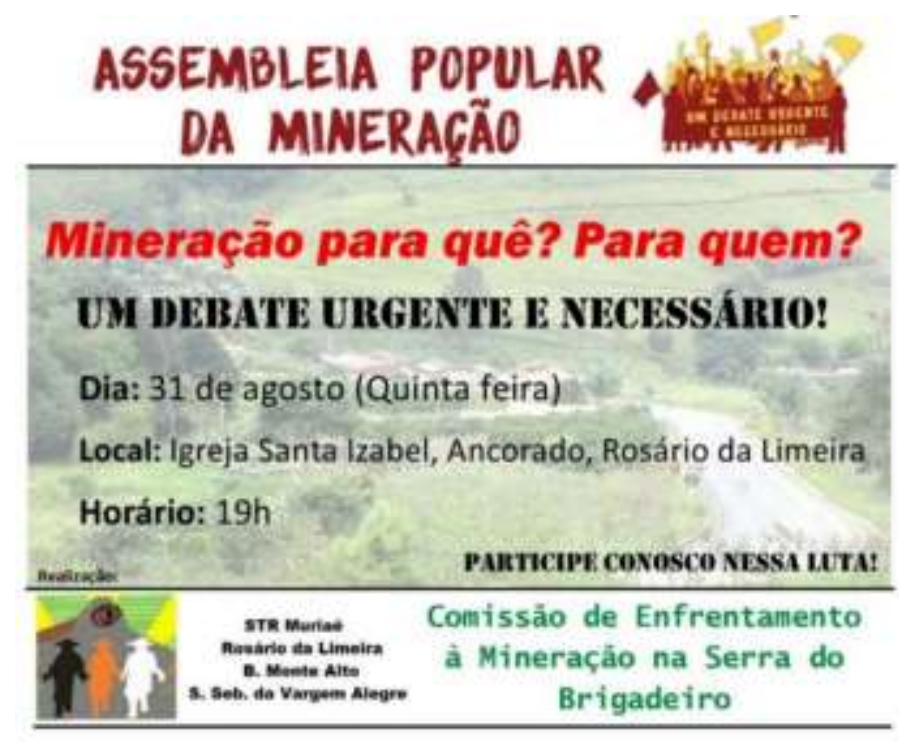

Fonte: Pesquisa de campo (2017).

No caso das audiências, destaca-se a realizada em junho de 2017, tal evento tinha por objetivo tratar das questões relativas a supostas violações dos direitos humanos cometidos pelo Grupo CBA/Votorantim na região da Serra do Brigadeiro. Além disso, o Projeto também contribuiu na produção de materiais para "Caminhada das águas”, realizada em Viçosa (MG), no dia 22 de março de 2017.

$\mathrm{O}$ PACAB também participou das reuniões referente à construção da Troca de Saberes ${ }^{3}$, as quais ocorreram no decorrer de julho de 2017, em diversos espaços da UFV, a exemplo das repartições do museu de solos, assim como, na casa dos movimentos sociais. As reuniões, compostas por professores e alunos, possuíam um caráter educativo construtivo, nesses espaços foi possível trazer para o debate, a experiência do Projeto acerca da temática ambiental e dos impactos da mineração na região. Conforme apontam Marques et al (2017), as ações de experiências semelhantes como essas, trazem do ponto de vista múltiplos sentidos nos espaços de aprendizagem, permitindo conferir a troca de experiência com outros grupos de extensão universitária, enriquecendo, assim, o curriculum e a vivência de estudantes e professores, participantes desses projetos.

Sendo assim, o PACAB, na Troca de Saberes, ministrou uma oficina a qual foi contemplada com mais de 50 participantes - os quais formaram um público diversificado, contando com a participação de estudantes e professores da UFV, moradores do município de Viçosa (MG) e membros de movimentos sociais organizados, podendo citar o Movimento de Atingidos por Barragens (MAB), Movimento Pela Soberania Popular na Mineração (MAM) e o Movimento dos Trabalhadores Rurais Sem Terra (MST). A oficina, previamente dita, discutiu a questão dos impactos das barragens e dos empreendimentos minerários a partir da exibição do documentário "Eu estou aqui”, produzido e dirigido por duas graduandas, do curso de Comunicação Social - Jornalismo da UFV: Taiane Caroline de Souza e Laira Abreu Carnelós. Documento esse que traz depoimentos de possíveis atingidos pelo mineroduto da Ferrous ${ }^{4}$ e de participantes da Campanha Pelas Águas. Assim, nesse espaço, procurou-se problematizar os efeitos danosos dos empreendimentos minerários junto ao meio ambiente e populações

\footnotetext{
${ }^{3}$ A Troca de Saberes é um evento que ocorre na Semana do Fazendeiro da Universidade Federal de Viçosa. Neste espaço ocorre um conjunto de atividades, que são construídas de forma compartilhadas voltadas para experiências cotidianas, valorizando os conhecimentos tradicionais no espírito da Educação Popular.

${ }^{4}$ A Empresa Ferrous no segundo semestre de 2016 desistiu da implantação do mineroduto na região. Sendo considerado uma vitória para os membros da Campanha.
} 
atingidas, desenvolvendo, a partir de discussões e relatos, trocas de experiências e de táticas utilizadas na resistência de comunidades diretamente atingidas por empreendimentos minerários.

Os membros do Projeto também participaram de reuniões organizadas por movimentos como Movimento pela Soberania da Mineração (MAM), Movimento dos Atingidos por Barragens (MAB), e outros grupos da UFV. Assim construindo uma rede de apoio as comunidades atingidas pela mineração na região de atuação do Projeto.

No que tange aos impactos do Projeto, percebe-se que as ações promovidas, fruto das parcerias com ONG's, Movimentos Sociais (MAM), Sindicatos de Trabalhadores Rurais (STRs) e Comissão Pastoral da Terra (CPT) junto às comunidades do território anteriormente citado, tem, por um lado, potencializado o desenvolvimento nesse território de uma Rede de articulação contra os impactos causados pela mineração e por outra via, tem potencializado junto as comunidades, o espírito da coletividade e da organização, contribuindo portanto, para que essas famílias possam construir coletivamente caminhos e diretrizes para o enfrentamento de desafios futuros apontados pelos planos e cenário da mineração. No final de 2017 foram realizadas uma série de eventos como um ato cultural em Rosário da Limeira (MG). Eventos esses que trouxeram, o debate dos impactos da mineração para o município através da arte. Bem como de uma outra reunião acerca de mais esclarecimentos da temática em pauta, realizada neste próprio munícipio em abril de 2017.

Salienta-se, ainda, a realização do seminário intitulado "Diferentes Formas de Dizer Não: experiências de proibição, resistência e restrição à mineração", ocorrido em 2019 na cidade de Muriaé, estimando-se que aproximadamente 120 pessoas de todo o país tenham participado do evento (Dotta, 2019, on line).

Os coletivos de resistência e mobilização popular tem solidificado sua articulação regional, com a realização de importantes atos de enfrentamento à atividade extrativa, o que corrobora para que o lema de "Serra do Brigadeiro, Território Livre de Mineração: Mineração? Aqui não" ganhe evidência regional e simbolize de forma muito marcante a importância da mobilização popular e do apoio de movimentos sociais, projetos de extensão universitária, dentre outros atores de suma importância para esse processo de construção de uma frente de resistência coletiva que inspira outras regiões que podem estar inseridas no âmbito de conflitos ambientais dessa natureza. A exemplo da promoção da "Carreata contra a Mineração, em defesa da Serra do Brigadeiro" organizada pela Comissão Regional de Enfrentamento à Mineração na Serra do Brigadeiro, ocorrida em 26/06/2021 na cidade de Rosário da Limeira-MG, com o lema "Mineração Aqui Não" conforme pode-se observar na Figura 3 o emblema da campanha.

Figura 3. Resistência à Mineração na Serra do Brigadeiro.

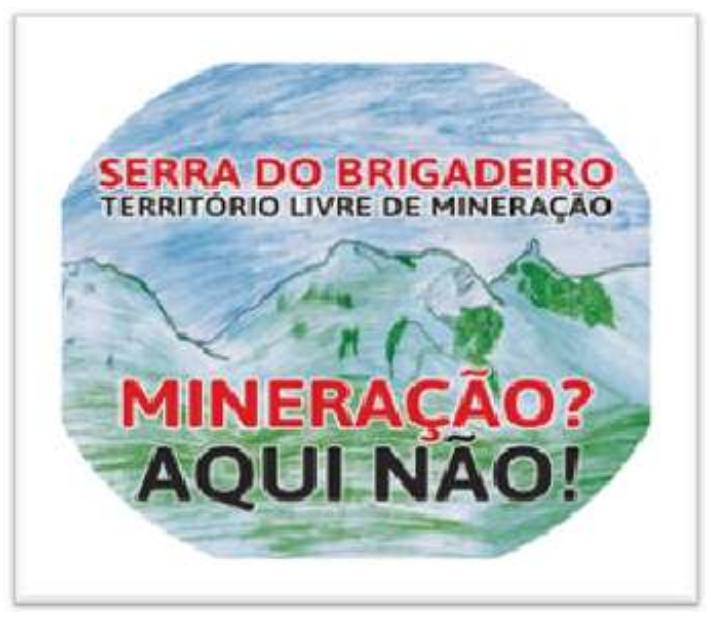

Fonte: MAM Nacional, 2020. 
Como já apontado anteriormente, tais iniciativas buscaram trazer luz ao debate, os efeitos e impactos causados pela atividade minerária na região do Parque Estadual da Serra do Brigadeiro. Assim, espaços criados foram importantes para aprofundar o debate sobre tema, intensificar a luta e conscientizar as comunidades sobre as consequências da exploração de bauxita na região, bem como da importância de se manterem organizados para enfrentar as consequências que virão dessa exploração.

\section{Considerações Finais}

Ao longo dos anos, o trabalho de assessoria estabeleceu uma série de parcerias que vão desde as comunidades atingidas, passando pelos sindicatos, movimentos sociais e até mesmo ONG’s. Essas parcerias estão ligadas principalmente a necessidade que os grupos têm em buscar conhecimento acadêmico e científico que possa servir de subsídio para o enfretamento junto ao processo de licenciamento. Por outro lado, essas parcerias têm permitido que a equipe do PACAB vivencie de perto essa realidade que, a cada dia, tem sido mais presente na região, contribuindo na articulação das comunidades atingidas e trazendo luz ao debate dos impactos causados pela mineração na região.

Nesse sentido, tais vivências proporcionam o compartilhamento das múltiplas experiências do Projeto, além de promoverem debates para diversos coletivos. A partir de 2019, algumas comunidades de Teixeiras (MG), município circunvizinho de Viçosa (MG), se identificaram enquanto atingidas pela mineração, demandando ações não só do PACAB, mas também de diversos grupos comprometidos com essa temática na região. Insta salientar que em decorrência do início de atividades de extração mineral no município de Teixeiras (MG) outras cidades da região passaram a registrar impactos oriundos do escoamento do minério, o que amplia a atuação do PACAB em pesquisas acerca dos efeitos (positivos e/ou negativos) da atividade minerária, bem como de outros atores sociais.

As experiências do Projeto, também, são compartilhadas nas aulas das disciplinas de Graduação ERU 451 (Extensão Rural) e ERU 380 (Desenvolvimento Socioeconômico), disciplinas que são ofertadas para estudantes de diversos cursos da universidade, tais como Agronomia, Zootecnia, Geografia, Serviço Social, Veterinária, Cooperativismo, entre outros. Além disso, as ações do Projeto contribuíram para a integração com a Pós-Graduação em Extensão Rural através da disciplina ERU 734 Conflitos Ambientais, disciplina que tem por objetivo proporcionar aos estudantes teorias e instrumentos de reflexões sobre a diversidade de conflitos socioambientais que emergem em meio às distintas realidades e diversas representações e significações que ajudam a explicar e esclarecer os conflitos em algumas de suas dimensões. Neste caso essa experiência pesquisada, serve como elementos empíricos para o debate dessa temática.

Os autores acreditam também, que as experiências adquiridas e os estudos desenvolvidos pelo PACAB transcendem ao ambiente acadêmico, atuando também no assessoramento aos atingidos e, principalmente em um convite ao diálogo à toda a sociedade civil (poder público, atingidos, população em geral, movimentos sociais, acadêmicos, técnicos) sobre a temática dos efeitos dos empreendimentos hidroelétricos e minerários, o que futuramente pode contribuir para a construção de diversos instrumentos sociais, a exemplo de políticas públicas, expansão de estudos sobre o tema, criação de órgãos ou conselhos municipais destinados à discussão do tema, dentre outros, principalmente no estado de Minas Gerais que nos últimos anos vem sofrendo com desastres e destruições provocados por atividades relacionadas a mineração como os ocorridos nos municípios de Mariana (2015) e Brumadinho (2019).

\section{Agradecimentos}

Os autores agradecem à Coordenação de Aperfeiçoamento de Pessoal de Nível Superior - Brasil (CAPES), pelo apoio na realização dessa Pesquisa. Código de Financiamento 001. 


\section{Referências}

Araujo, E. R.; Olivieri, R. D. \& Fernandes, F. R. C. Atividade mineradora gera riqueza e impactos negativos nas comunidades e no meio ambiente. In: Recursos minerais e comunidade: impactos humanos, ambientais e econômicos / Francisco Rego Chaves Fernandes, Renata de Carvalho Jimenez Alamino, Eliane Araujo (Eds.). CETEM/MCTI, 392p.: il, 2014.

Benites, V. M. (1998). Caracterização química e espectroscópica da matéria orgânica e suas relações com a gênese de solos da Serra do Brigadeiro, Zona da Mata mineira. Viçosa, Universidade Federal de Viçosa, 1998, 125p. (Tese de Mestrado)

Comitê Nacional em Defesa dos Territórios frente à mineração. (2019). Programação completa do Seminário "Diferentes Formas de Dizer Não". Comitê Nacional em defesa dos territórios frente à mineração. http://emdefesadosterritorios.org/661-

Dotta, R. (2019). Em Muriaé (MG), seminário reúne diversas formas de dizer não à mineração. Brasil de Fato. https://www.brasildefatomg.com.br/2019/08/21/em-muriae-mg-seminario-reune-diversas-formas-de-dizer-nao-a-mineracao.

Fenelon, A. N. (2018). Para quê e para quem é este cano? Registros e processos de enfrentamento à mineração extrativista a partir da microrregião de Viçosa/MG [dissertação de mestrado em Extensão Rural, Universidade Federal de Viçosa-MG]. Locus Repositório Institucional da UFV. https://locus.ufv.br//handle/123456789/24862.

Fonseca. J. J. S. da. Metodologia da Pesquisa Científica. Curso de especialização em comunidades virtuais de aprendizagem - informática educativa. Universidade Estadual do Ceará, Fortaleza, 2002.

Freire, P. (1988). Extensão ou Comunicação? Paz e Terra.

Gazeta de Muriaé. (2017). Assembleia Popular em Rosário da Limeira reivindica demarcação de Serra do Brigadeiro como território livre de mineração. Gazeta de Muriaé. http://www.gazetademuriae.com.br/site/noticia/detalhe/8276/assembleia-popular-em-rosario-de-limeira-reivindica-demarcacao-da-serrado-brigadeiro-como-territorio-livre-de-mineracao.

Guedes, G. B. (2015). Mineração e movimentos sociais [dissertação de mestrado, Universidade Federal Rural do Rio de Janeiro, Instituto de Ciências Humanas e Sociais, 2015.

Instituto Estadual de Florestas (IEF). Parque Estadual da Serra do Brigadeiro. http://www.ief.mg.gov.br/component/content/197?task=view.

Iorio, G. S. \& Magno, L. Cartografia Social e diversidade territorial no enfrentamento à mineração na Serra do Brigadeiro. XIII ENANPEGE 2019/ A Geografia brasileira na ciência-mundo: produção, circulação e apropriação do conhecimento. https://www.ufjf.br/poemas/files/2014/08/Iorio-2019Cartografia-social.pdf.

Iorio, G. S. \& Magno, L. (2019). O território corporativo da mineração na Serra do Brigadeiro, Minas Gerais. Revista Sapiência: Sociedades, Saberes e Práticas Educacionais,. 8(2), 34-50. Dossiê: Extrativismo Mineral, conflitos e resistências no Sul Global. https://www.ufjf.br/poemas/files/2014/08/Iorio2019-O-territ\%c3\%b3rio-corporativo-da-minera\%c3\%a7\%c3\%a3ona-serra-do-brigadeiro.pdf.

Magno, L. (2017). Espacialidade e identidade política dos atingidos por mineração no Brasil: teorias, escalas e estratégias [tese de Doutorado em Geografia, UFSC, Florianópolis-SC). Repositório Institucional UFSC. https://repositorio.ufsc.br/handle/123456789/186603.

Magno, L.; Siqueira, L. P. G. \& Delesposte, A. G. (2017). "MINERAÇÃO? AQUI NÃO!”: a construção da resistência à mineração de bauxita na Serra do Brigadeiro, Minas Gerais. SINGA 2017/VIII Simpósio Internacional de Geografia Agrária. https://www.ufjf.br/poemas/files/2014/08/Minera\%c3\% a7\% $3 \%$ a3o-Aqui-n\%c3\%a3o-2017.pdf.

Marques, B, R. R.; Lima, L. B. \& Emerich, R. C. S. Extensão Como Mediação didática: troca de Experiências e saberes no Quilombo São José da Serra. In: Caminho Aberto - Revista de Extensão do IFSC.

Movimento pela Soberania Popular na Mineração (MAM). (2020, 26 de maio). Comissão de Enfrentamento à Mineração na Serra do Brigadeiro aciona justiça para obter audiência pública. MAM Nacional. http://mamnacional.org.br/2020/05/26/comissao-de-enfrentamento-a-mineracao-na-serra-do-brigadeiroaciona-justica-para-obter-audiencia-publica/.

Netto, M. M. \& Diniz, A. M. A. (2006). A formação geohistórica da Zona da Mata de Minas Gerais. Rev. RA 'E GA. Ed. UFPR. $12,21-34$.

Oliveira, M. L. R. \& Sousa, D. N. (2015). Experiência de assessoria junto às comunidades atingidas pelo mineroduto da Ferrous na Zona da Mata mineira. Extensio: R. Eletr. de Extensão. 12(19), 61-69.

Pereira, A. S; Shitsuka, D. M.; Parreira, F. J. \& Shitsuka, R. (2018). Metodologia da Pesquisa Científica. UFSM.

Portal Miradouro. (2021). Carreata contra a mineração na Serra do Brigadeiro. Portal Miradouro. http://www.portalmiradouro.com.br/site/2 021/06/16/carreata-contra-a-mineracao-na-serra-do-brigadeiro/.

Portal Miradouro. (2021). Carreata em defesa da Serra do Brigadeiro e contra a mineração é realizado em Rosário da Limeira. Portal Miradouro. http://www.portalmiradouro.com.br/site/2021/06/28/carreata-em-defesa-da-serra-do-brigadeiro-e-contra-a-mineracao-e-realizado-em-rosario-da-limeira/.

Silva, D. M. da, Cordeiro, J., Calazans, G. M., Alvarenga, C. A. de \& Cordeiro, J. L. (2018). Percepção dos moradores de Barão de Cocais (MG) acerca da criação do Parque Nacional da Serra do Garandela e dos impactos desencadeados pela atividade minerária. Research, Society and Development, 8(1), 1-20. https://rsdjournal.org/index.php/rsd/article/view/116/146

Zhouri, A. \& Rothman, F. D. Assessoria aos atingidos por barragens em Minas Gerais: desafios, limites e potencial. Em Rothman, F.D. (Org.). Vidas alagadas: conflitos ambientais, licenciamento e barragens. UFV. 